\title{
CLINICAL ASSESSMENT IN PSORIATIC ARTHRITIS
}

\author{
C. SALVARANI, N. PIPITONE, M.G. CATANOSO \\ Unit of Rheumatology, Hospital of Reggio Emilia, Reggio Emilia, Italy
}

\begin{abstract}
SUMMARY
Due to the heterogenous clinical picture, with a possible combination in any individual patient of axial disease, peripheral arthritis, enthesitis and dactylitis, psoriatic arthritis (PsA) is difficult to assess. Validated assessment tools for PsA are lacking. Recently, international study groups have a special interest in developing and validating standardized tools to assess PSA. We will review the existing assessment modalities of PsA focusing on axial diasese, peripheral arthritis, enthesitis and dactylitis. Measures of function and disability recommended for PsA will be also reviewed.
\end{abstract}

Key words: Psoriatic arthritis, assessment tools, clinical trials

\section{BACKGROUND}

Psoriatic arthritis (PsA) is a chronic inflammatory disorder characterized by arthritis and psoriasis variably associated with other extra-articular manifestations (1-5).

PsA is usually grouped among the seronegative spondyloarthropathies ( $\mathrm{SpA})$, a class of diseases encompassing ankylosing spondylitis (AS) and reactive arthritis, with which it shares a number of common immunogenetical, radiological, and clinical features (1-5).

PsA has traditionally been considered a milder and less disabling disease compared with rheumatoid arthritis (RA). However, this view has recently been challenged by a number of studies showing that approximately $40 \%$ of PsA patients develop joint erosions and damage $(6,7)$. In addition, in circa $20-40 \%$ of patients, PsA can also affect the axial skeleton (so-called "psoriatic spondylitis") (8), leading to functional limitation and deformity akin to, although usually less severe than that observed in AS (9).

Due to the heterogenous clinical picture, with a possible combination in any individual patient of axial disease, peripheral arthritis, enthesitis and dactylitis,

\footnotetext{
Corresponding author:

Carlo Salvarani, MD

Servizio di Reumatologia

Arcispedale S. Maria Nuova

V.le Risorgimento N80

42100 Reggio Emilia, Italy

E-mail: salvarani.carlo@asmn.re.it
}

PsA is difficult to assess and validated assessment tools are lacking. Recently, the Group for Research and Assessments in Psoriasis and Psoriatic Arthritis (GRAPPA) has contributed to the development and validation of standardized tools to assess PsA. We will review the existing assessment modalities of PsA focusing on axial diasese, peripheral arthritis, enthesitis and dactylitis. Measures of function and disability recommended for PsA will be also reviewed.

\section{PERIPHERAL JOINT DISEASE}

\section{Peripheral joint disease activity}

Assessments of peripheral joint disease activity in PsA include the American College of Rheumatology (ACR) joint count, the Ritchie index and the 28-joint count (10-12).

The ACR joint count documents the number of joints with joint-line tenderness, stress pain, and/or swelling. The total joint count (total number of tender and/or swollen joints) may be calculated, or separately the sum of the number of tender joints or swollen joints. The ACR joint count is valid in RA both in terms of its reproducibility and in terms of its sensitivity to change with time. The ACR joint count is a reliable measure of disease activity also in PsA, however it has not been tested specifically for sensitivity to change over time.

The Ritchie index assesses the individual joints according to the ACR joint count. It includes the degree of tenderness and swelling of each joint on 
Table I - Application of the PsARC as an outcome measures in recent PsA clinical trials.

\begin{tabular}{|llcc|}
\hline Study drug (duration) & Trial (No. of patients) & PSARC, \% responders \\
\hline Sulfasalazine (36 weeks) & Clegg et al. (220) & 55 & 45 \\
Etanercept (12 weeks) & Mease et al. (60) & 87 & 23 \\
Infliximab (16 weeks) & Antoni et al. (100) & 76,5 & 18 \\
Etanercept (24 weeks) & Mease et al. (205) & 70 & 24 \\
Leflunomide (24 weeks) & Kaltwasser et al (188) & 57,9 & 29,7 \\
Adalimumab (24 weeks) & Mease et al. (313) & 60 & 23 \\
\hline
\end{tabular}

a 0-3 scale, but it does not include the distal interphalangeal (DIP) joints of the feet. The Ritchie index demonstrated more observer-related variation than did the ACR joint count in RA.

The 28-joint count is a reduced joint count which includes both shoulders, elbows and wrists, all metacarpalphalangeal joints, all proximal interphalangeal joints of the hands, and both knees. It has been studied in RA, but it has not been validated in PsA. The 28-joint count could not be appropriate for PsA:

1) more than $50 \%$ of the patients have inflammation of the DIP joints;

2) in some patients arthritic manifestations are restricted to DIP joints;

3) foot involvement is common in PsA.

\section{Measures used to assess peripheral joint disease in recent clinical trials in $P$ s A}

Psoriatic Arthritis Response Criteria (PsARC), ACR response criteria (20,50 e 70\%) and EULAR response criteria based on Disease Activity Score (DAS) were used to assess joint disease in recent clinical trials in PsA (13-18). These response measures include: assessment of tender and swollen joints and patient - and physician - derived scores. They successfully distinguished drug-treated from placebo-treated patients.

Psoriatic Arthritis Response Criteria were developed by Clegg et al for the study of sulfasalazine in PsA (13). They include:
- Physician global assessment (0-5 point scale) (response: reduction by 1 score).

- Patient global assessment (0-5 point scale) (response: reduction by 1 score).

- Tender joint count (76 or 68) (response: reduction of $>30 \%$ ).

- Swollen joint count: (76 or 68) (response: reduction of $>30 \%$ ).

Overall response is defined by improvement in 2 of 4 items, one of which must be a joint count; there must not be worsening in any of the 4 items. In recent PsA clinical trials where PsARC where used as primary or secondary outcome measures, they demonstrated differences between the drug and placebo-treated patients (Table I) (13-18). Therefore these criteria are a valid outcome measure in PsA.

ACR response criteria (20, 50 e $70 \%$ ) have been extensively used in RA clinical trials. They include: $20 \%(50 \%$ or $70 \%)$ reduction in the tender joint count

$20 \%(50 \%$ or $70 \%)$ reduction in the swollen joint count

\section{a $20 \%$ (50 or $70 \%$ ) reduction in}

3 of the following 5 additional measures: patient and physician global assessments (VAS) patient pain score (VAS) disability (HAQ) acute phase reactant (ESR or CRP)

Table II - Application of the ACR 20\% improvement response criteria as an outcome measures in recent PsA clinical trials.

\begin{tabular}{|llcc|}
\hline Study drug (duration) & Trial (No. of patients) & ACR20, \% responders & placebo group \\
\hline Etanercept (12 weeks) & & drug group & 13 \\
Infliximab (16 weeks) & Mease et al. (60) & 73 & 8 \\
Etanercept (24 weeks) & Antoni et al. (100) & 69 & 13 \\
Adalimumab (24 weeks) & Mease et al. (205) & 50 & 15 \\
Leflunomide (24 weeks) & Mease et al. (313) & 57 & 20 \\
\hline
\end{tabular}


In PsA clinical trials the total number of joints counted was increased to 78 for tenderness and 76 for swelling, including the 66 or 68 joints routinely evaluated in an ACR joint count plus 10 additional joints often involved in PsA (the first carpometcarpal and the DIP joints of the toes).

These criteria were included as outcome measures (primary or secondary) in recent PsA clinical trials and the differences observed in the responses between drug- and placebo-treated patients indicate that ACR response criteria for RA have validity in PsA trials (Table II) (14-18).

EULAR response criteria are based on the Disease Activity Score (DAS):

- Ritchie Articular Index

- Swollen Joint Count

- ESR (mm/hour)

- Patients general health or global disease activity (VAS).

The EULAR response criteria include not only change in disease activity, but also current disease activity. To be classified as responders (good or moderate), patients should have a significant change in DAS and also low current disease activity. The DAS 28 includes only 28 joints.

A comparable validity for the EULAR and ACR response criteria was demonstrated in RA.

In evaluating PsA disease activity EULAR response criteria have the major limitation of excluding distal interphalangeal joints.

The DAS and DAS 28 were evaluated as secondary outcomes in the Infliximab Multinational Psoriatic Arthritis Controlled Trial ( IMPACT) and they distinguished infliximab from placebo-treated patients at 16 weeks (15).

In conclusion, based on their ability to distinguish between drug-treated and placebo-treated patients, the ACR, PsARC, and EULAR response criteria for outcome assessment in RA appear to be valid in the assessment of peripheral arthritis in PsA.

\section{SPINAL DISEASE}

Spondylitis occurs in $\sim 40 \%$ of patients with PsA, but it is less severe than that of AS. Therefore, it is possible that measures of axial disease originally developed for AS may not be sufficiently sensitive to change or accurate for use in PsA. The assessment of spinal disease has not been included in clinical PsA trials to date, as there are no acceptable tools.
The most widely used measure of the inflammatory activity of AS is the Bath Ankylosing Spondylitis Disease Activity Index (BASDAI) which evaluates:

- VAS overall level of fatigue/tiredness past week

- VAS overall level of AS neck, back, or hip pain past week.

- VAS overall level of pain/swelling in joints other than neck, back or hips past week.

- VAS overall discomfort from any areas tender to touch or pressure past week.

- VAS overall level of morning stiffness from time of awakening past week.

- Duration and intensity (VAS) of morning stiffness from time of awakening (up to 120 minutes).

BASDAI is simple, patient-completed, sensitive to change over 3-weeks, and has been validated in AS. Assessments in Ankylosing Spondylitis (ASAS) Working Group have recommended that significant clinical benefit in SA treatment is indicated by reduction of BASDAI by $50 \%$ or a fall of 2 units (19). However there are some limitations in using BASDAI as an outcome measure for PsA. BASDAI did not distinguish between patients with PsA with a spondylarthropathy and those without (20). BASDAI performs similarly for axial and peripheral PsA, but does not correlate well with external indicators of disease activity, such as treatment decisions (21). In conclusion, waiting for further studies of validation in PsA, BASDAI do no function well and it is ambiguous as a measure of disease activity in patients with PsA.

ASAS response criteria are a clinically valid, easy-to-use measure of short term improvement in AS validated in clinical trials (19). ASAS 20 or $40 \%$ response criteria could be used to measure axial PsA disease activity and to assess therapeutic response, but they must be validated in this condition. ASAS 20 improvement criteria include: improvement of $\geq 20 \%$ and $\geq 10$ units in at least 3 of the following 4 domains: patient global assessment, pain, function, inflammation + no worsening of $\geq 20 \%$ and $\geq 10$ units in the remaining domain.

\section{DACTYLITIS}

Dactylitis occurs in 16-48\% of cases of PsA (22). Acute dactylitis has been shown to be a clinical indicator of disease severity. However, chronic, nontender diffuse dactylitic swelling may be less clini- 
cally significant. An instrument suitable for quantifying psoriatic dactylitis must be able to measure the amount of swelling and distinguish tender from nontender digits. At the moment, there are no validated, sensitive measure for dactylitis. In our practice we use a $0-2$ scale $(0=$ none, $1=$ present but minimal, $2=$ present and maximal) and we count all 20 digits where dactylitis is present (the joints in that digit are not scored separately). Recently, a new method for quantifying dactylitis based on digital circumference and tenderness has been described with a good inter and intraobserver reliability (23).

\section{Measures used to assess dactylitis in recent clin- ical trials in PsA}

A simple scoring of present or absent dactylitis was used in the IMPACT trial with infliximab (15), in which statistically significant improvement of dactylitis was demonstrated in the infliximab group. Dactylitis was evaluated using a 0-3 scale, based on the clinician's judgement of relative severity, for each digit of the hand and toes in the trial with adalimumab (18). In this trial dactylitis improved, but the changes did not achieve statistical significance comparing adalimumab treatment group to placebo group.

\section{ENTHESITIS}

Two enthesitis measures have been developed for spondyloarthropathies: the Mander index and the Maastricht Ankylosing Spondylitis Enthesis Score (MASES) $(24,25)$. The Mander index, which includes 66 sites, has been considered cumbersome because of the large number of sites assessed. The MASES index, which includes 13 anatomic sites is more simple, has been validates in patients with AS, but it has not yet been assessed in PsA trials.

\section{Measures used to assess enthesitis in recent clin- ical trials in PsA}

Enthesitis was defined as present or absent on the plantar fascia and insertion of the Achilles tendons bilaterally. Enthesitis was significantly improved with infliximab treatment but not with adalimum$\mathrm{ab}$ treatment compared to placebo $(15,18)$.

\section{MEASURES OF FUNCTION AND DISABILITY}

The following measures of function and disability were validated in PsA: the Health Assessment
Questionnaire (HAQ) which assesses function related to arthritis and the Medical Outcomes Study Short-Form 36 (SF-36) which is a generic quality of life instrument (11).

A new quality of life measure (PsAQol) has been recently developed for PsA but it requires validation (26).

The Health Assessment Questionnaire was developed by Fries et al for the assessment of disability in patients with RA (27). HAQ focuses on physical disability (8 scales) and pain. A modification of the HAQ for spondyloarthropaties (HAQS) was also developed, which includes 2 spinal domains. A further modification, HAQ for psoriasis (HAQ-SK) was also studied in PsA patients.

Both HAQ and HAQ-S were tested in PsA patients, both correlated with disease activity, and their scores were almost identical. HAQ has been used in several PsA therapy trials (11).

SF-36 is a generic health assessment questionnaire, which has been studied in a number of chronic diseases including rheumatic conditions. SF-36 assesses 8 domains: physical functioning, pain, vitality, social functioning, psychological functioning, general health perceptions, and role limitations due to physical and emotional problems. SF-36 has been validated in PsA. In PsA SF-36 was equally or more responsive than HAQ to short term changes in perceived health status and inflammatory disease activity. SF-36 has been used in several PsA therapy trials (11).

\section{Measures used to assess function and disability in recent clinical trials in PsA}

Recently randomized controlled trials with antiTNF agents and leflunomide demonstrated significant reductions in HAQ scores in the patient group treated with the active drug compared to placebo group. SF-36 has also demonstrated significant improvement in recent PsA therapeutic trials (15-18).

\section{REFERENCES}

1. Salvarani C, Olivieri I, Cantini F, Macchioni L, Boiardi L. Psoriatic arthritis. Curr Opin Rheumatol 1998; 10: 299-305.

2. Olivieri I, Cantini F, Salvarani C. Diagnostic and classification criteria, clinical and functional assessment, and therapeutic advances for spondyloarthropaties. Curr Opin Rheumatol 1997; 9: 284-90.

3. Olivieri I, Van Tubergen A, Salvarani C, Van Der Linden S. Seronegative spondyloarthritides. Best Pract Res Clin Rheumatol 2002; 16: 723-39. 
4. Palazzi C, Olivieri I, Petricca A, Salvarani C. Rheumatoid arthritis or psoriatic symmetric polyarthritis? A difficult differential diagnosis. Clin Exp Rheumatol 2002; 20: 3-4.

5. Salvarani C, Lo Scocco G, Macchioni P, Cremonesi T, et al. Prevalence of psoriatic arthritis in italian psoriatic patients. J Rheumatol 1995; 22: 1499-503.

6. Gladman DD, Shuckett R, Russell ML, Thorne JC, Schachter RK. Psoriatic arthritis (PSA)-an analysis of 220 patients. Q.J.Med. 1987; 62: 127-41.

7. Gladman DD, Stafford-Brady F, Chang CH, Lewandowski K, Russell ML. Longitudinal study of clinical and radiological progression in psoriatic arthritis. J.Rheumatol. 1990; 17: 809-12.

8. Gladman DD. Psoriatic arthritis. Rheum.Dis.Clin.North Am. 1998; 24: 829-44, x.

9. Helliwell PS, Hickling P, Wright V. Do the radiological changes of classic ankylosing spondylitis differ from the changes found in the spondylitis associated with inflammatory bowel disease, psoriasis, and reactive arthritis? Annals of the Rheumatic Diseases 1998; 57: 135-40.

10. Gladman DD, Farewell V, Buskila D, Goodman R, Hamilton L, Langevitz P et al. Reliability of measurements of active and damaged joints in psoriatic arthritis. J.Rheumatol. 1990; 17: 62-4.

11. Gladman DD, Helliwell P, Mease PJ, Nash P, Ritchlin C, Taylor W. Assessment of patients with psoriatic arthritis: a review of currently available measures. Arthritis Rheum. 2004; 50: 24-35.

12. Salvarani C, Olivieri I, Pipitone N, Cantini F, et al. Recommendations of the Italian Society for Rheumatology for the use of biologic (TNF-alpha blocking) agents in the treatment of psoriatic arthritis. Clin Exp Rheumatol. 2006; 24: 70-8.

13. Clegg DO, Reda DJ, Mejias E, Cannon GW, Weisman $\mathrm{MH}$, Taylor $\mathrm{T}$ et al. Comparison of sulfasalazine and placebo in the treatment of psoriatic arthritis. A Department of Veterans Affairs Cooperative Study. Arthritis Rheum. 1996; 39: 2013-20.

14. Mease PJ, Goffe BS, Metz J, VanderStoep A, Finck B, Burge DJ. Etanercept in the treatment of psoriatic arthritis and psoriasis: a randomised trial. Lancet 2000; 356: 385-90.

15. Antoni CE, Kavanaugh A, Kirkham B, Tutuncu Z, Burmester GR, Schneider U et al. Sustained benefits of infliximab therapy for dermatologic and articular manifestations of psoriatic arthritis: results from the infliximab multinational psoriatic arthritis controlled trial (IMPACT). Arthritis Rheum. 2005; 52: 1227-36.
16. Mease PJ, Kivitz AJ, Burch FX, Siegel EL, Cohen SB, Ory $\mathrm{P}$ et al. Etanercept treatment of psoriatic arthritis: safety, efficacy, and effect on disease progression. Arthritis Rheum. 2004; 50: 2264-72.

17. Kaltwasser JP, Nash P, Gladman D, Rosen CF, Behrens $\mathrm{F}$, Jones $\mathrm{P}$ et al. Efficacy and safety of leflunomide in the treatment of psoriatic arthritis and psoriasis: a multinational, double-blind, randomized, placebo-controlled clinical trial. Arthritis Rheum. 2004; 50: 1939-50.

18. Mease PJ, Gladman DD, Ritchlin CT, Ruderman EM, Steinfeld SD, Choy EH et al. Adalimumab for the treatment of patients with moderately to severely active psoriatic arthritis: results of a double-blind, randomized, placebo-controlled trial. Arthritis Rheum. 2005; 52: 3279-89.

19. Braun J, Pham T, Sieper J, Davis J, van der LS, Dougados $\mathrm{M}$ et al. International ASAS consensus statement for the use of anti-tumour necrosis factor agents in patients with ankylosing spondylitis. Ann.Rheum.Dis. 2003; 62: 817-24.

20. Brockbank JB, Schimmer K, Schentag C, et al. Spinal disease assessment in psoriatic arthritis. J Rheumatol 2001; 28 (suppl 63): 62.

21. Taylor WJ, Harrison AA. Could the Bath Ankylosing Spondylitis Disease Activity Index (BASDAI) be a valid measure of disease activity in patients with psoriatic arthritis? Arthritis Rheum. 2004; 51: 311-5.

22. Salvarani C, Cantini F, Olivieri I, Macchioni P, Niccoli L, Padula A et al. Isolated peripheral enthesitis and/or dactylitis: a subset of psoriatic arthritis. Journal of Rheumatology 1997; 24: 1106-10.

23. Helliwell PS, Firth J, Ibrahim GH, Melsom RD, et al. Development of an assessment tool for dactylitis in patients with psoriatic arthritis. J Rheumatol 2005; 32: 1745-50.

24. Mander M, Simpson JM, McLellan A, et al. Studies with an enthesitis index as a method of clinical assessment in ankylosing spondylitis. Ann Rheum Dis 1987; 46: 197-202.

25. Heuft-Dorenbosch L, Spoorenberg A, van Tubergen A, Landewe R, van ver TH, Mielants $\mathrm{H}$ et al. Assessment of enthesitis in ankylosing spondylitis. Ann.Rheum.Dis. 2003; 62: 127-32.

26. McKenna SP, Doward LC, Whalley D, Tennant A, et al. Development of the PsAQoL: a quality of life instrument specific to psoriatic arthritis. Ann Rheum Dis 2004; 63: 162-9.

27. Fries JF, Spitz P, Kraines RG, Holman HH. Measurement of patient outcomes in arthritis. Arthritis Rheum 1980; 23: 127-45. 